\title{
Brief Analysis on Ceramic Culture of Yangwuling Kiln
}

\author{
Dehua $\mathrm{Yu}$ \\ Hunan City University \\ Yiyang, Hunan, China 413000
}

\begin{abstract}
Located in Dongting Lake region in the lower reaches of Yangtze River, Yangwuling kiln lies in the ancient town Yiyang. As a folk kiln factory during Song Dynasty and Qing Dynasty, its production of bluish white porcelain, glazed colored porcelain, blue and white porcelain, etc. embodies era characteristics of the particular historical period, and also has distinct geographical and cultural characteristics. The products appear unadorned modeling and rough decoration, with most decorative contents taking folk and local culture as themes, and abstract and impressionistic performance techniques. This paper explored the rich and unique folk culture value of Yangwuling kiln porcelain from the point of techniques and decorative art language.
\end{abstract}

\section{Keywords_-Yangwuling; ceramics; cultural image}

\section{INTRODUCTION}

"Yangwuling kiln" gained the name from its place, yet some scholars infer from the image on artifacts resembling goats, which could not be confirmed. Yangwuling kiln porcelains are mainly bluish white porcelain, most are practical utensils of ordinary people, so they weigh functions over decoration. The porcelain making craft was heavily influenced by the surrounding kilns, especially by Jingdezhen, some scholars have directly classified Yangwuling kiln into Jingdezhen porcelain system, and their strong ties can thus be seen.

Ever since the decline of the late Qing Dynasty, Yangwuling kiln has been deserted, resulting in desolation of this miracle civilian porcelain full of folk and local culture. Although there have been findings in recent years and local government has also changed by forging cultural economy, an in-depth and systematic research on ceramics is still required. Through research and analys is of the production process of Yiyang Yang Wulin kiln ceramics as well as collection of relevant textual and graphic files, this paper aims to give a comparative analysis of the entire process from molding to firing of porcelain, revealing the unique cultural appeal of this folk treasure and providing literature data for relevant research, protection and development.

\section{MOLDING PROCESS AND MODELING FEATURES}

Yangwuling kiln uses local kaolin, porcelain color is gray white, its viscosity is slightly inferior compared to Jingdezhen, Dehua and other places, which exerts a direct impact on its shape norms, molding and decoration techniques. "The utensils produced in the late Song Dynasty and early Yuan Dynasty were relatively small with thin body; from Yuan Dynasty to mid-Ming Dynasty, body became thick and utensils were larger; in late Ming Dynasty, bowls, plates, cups and other objects tended to be small and exquisite with thinner body, which resembled the artifacts of small dishes and bowls produced from folk Jingdezhen kilns in later Ming Dynasty."

Yangyuling kiln porcelain is mainly for local civil use in Hunan, also with production of export porcelain, its shape, glaze, decorative features fuse both north and south porcelain characteristics, with regular modeling, rich forms and diverse decoration, more round utensils than carving and polishing utensils. It can be seen from the existing utensils that early shapes are exquisite, with thin body and glaze being applied inside and outside, porcelain are clean and delicate; there are characteristics of extensive shape, thick body and insufficient fine trimming in the middle and later periods. The vessel shapes in current market are mostly bowls, plates, washers, cans, ewers, censers, cups, oil cups, ink stones, water droppers, etc., as well as a small nu mber of furnishings and burial objects, in which bowl shape is more complex, there are lotus petal bowls, bamboo hat bowls, pier bowls, bow bowls, etc. For instance, Song Qing - white lotus petals bowl "Fig.1", it has rich glaze, grey white color, heavy body, unglazed neck and shallow feet, flaring mouth and bow belly, outer wall engraved with lotus petals, the whole shape is seamless, harmonious and simple. Yuan -Yangwuling kiln black glaze cup, it has simple and generous modeling which is simple and elegant, with black glaze being applied on whole body, unglazed neck and shallow feet, curved belly; porcelain is relatively loose, with sand inclusion in bottom body, appearing typical characteristics of practical utensils made in southern kilns.

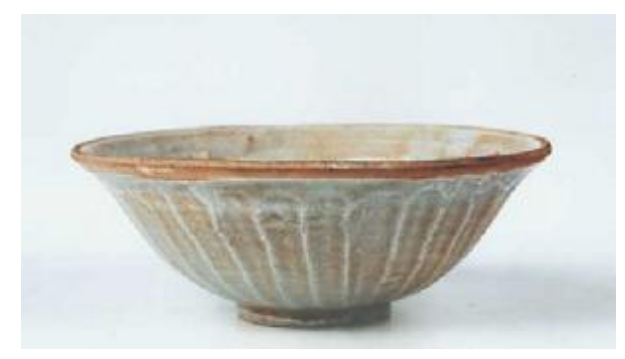

Fig. 1. Song Qing — white lotus petals bowl 
There are mainly two production methods for various types of porcelain in Yangwuling kiln, namely wheeler production and mould production, in which wheeler production is in the majority, carving and polishing utensils mainly adopt sectional cohesion production. The molding process adopts the generally applicable craft and techniques, even with foresight and innovation. Since most are small utensils, moulding by throwing is wheeler production, which is the main molding method. Whether it is moulding by throwing or mould production molding, the molding processes are complicated, patient production in every link is required in order to get a fine and complete cera mic artifact.

\section{A. Throwing and Moulding by Throwing of Carving and Polishing Utensils}

Yangwuling kiln produces a smaller amount of carving and polishing utensils, the large round utensils are adopt sectional production by throwing with a round utensil, then cohered by raw clay paste. The moulding of square and angular utensils is making into clay sheets with clay, and then cutting into blocks as required and cohering into shapes.

"Throwing", commonly known as "twirling clay", is an important mold ing method for the production of Yangwuling kiln chinaware. The moulding of throwing process is fast, with regular shape. Twirl along the potter's wheel and vertically pull the clay into columns, press downward and make an opening, obtain the desired shape by pushing. Clay treading and clay rubbing procedures are also important steps before throwing, which can uniform the moisture in clay, prevent deformation or cracking. Clay rubbing is known as "clay moving" in Jingdezhen, similar to the local pronunciation of Yiyang, which could not be confirmed whether being affected by Jingdezhen. Seen from the density of body, the clay material was coarse, with uneven granular size, inclusion in bottom body and insufficient clay rubbing procedures, but the rough pottery emits a rustic and artistic charm today.

Due to the lack of flexibility of clay, Yangwuling kiln porcelain mostly adopts sectional moulding by throwing, then joined by mud, forming comparatively thick body, obvious joints and insufficient fine trimming. The inwall and bottom of porcelain unearthed from Yangwuling kiln are mostly left with significant rotation patterns, some walls have brown eyes, which relate to clay features; the decline of Yangwuling kiln perhaps results from the defects in clay and the level of technology limitations at that time.

\section{B. Hand Pressing and Fine Trimming}

Hand pressing is an important procedure for the moulding of Yangwuling kiln ceramics, co mmonly known as patting dead head, used for moulding operation of inner surface of round greenware. Fine trimming is also known as wheeling, which is a manual moulding method by putting hand base or grouting base on fine trimming and trimming with a knife so as to make the utensil meeting the model specifications, as well as polishing.

Earlier chinaware fine trimming of Yangwuling kiln ceramics is in place, made delicately. Due to limitation of firing process, most kiln ceramics have unglazed necks. Products at later period are rougher. Perhaps in order to save process, crude green body moulding by hand directly adopts painting fire, or simply adopts one fine trimming. Sense of concavo-convex of junction in many ceramics is clear and brush mark of engobe at exposed body on ceramic bottom and foot is obvious. For example, bluish-white glaze rhombus pattern discoid bottle in Qing Dynasty adopts bamboo comb cutting process, shoulder decoration of blessing cloud head pattern, abdomen decoration of quilting and lotus pattern. Decoration pattern on the surface is removed and the shape is irregular and original state of throwing by hand is reserved, the body is thicker, especially obvious in discoid mouth and ring foot, the bottom foot is thicker and rotary pattern is very obvious; the foot is cut hastily and obvious tool mark is reserved.

\section{For Firing and Molding Process}

Yangwuling kiln mostly is built along the mountain, with simple structure. The kiln is comparatively narrow and short; the kiln floor is paved with sand, with small slope, from bottom to top. The kiln temperature is controlled evenly, and reducing atmosphere and temperature lifting can be controlled easily. The shape is Long kiln generally adopted since Shang Dynasty, which is composed of wicket, fire barrier bed, kiln chamber, s moke vent and so on. The most characteristic is to adopt the principle of natural lifting of fire by using slope height difference, and take full advantage of rise and flowing of heat and greatly expand placing and firing area inside kiln, but labor intensity of kiln placing and opening is huge, temperature fluctuation inside kiln is larger and it is inconvenient to place kiln.

Firing methods of Yangwuling kiln mainly include upward firing, upside down firing, nailed firing and heaping firing. The current dug kiln furniture mainly includes support ring, support ring pad, gasket, sagger, sagger pad, bedder, bracket, fire, strut and support, etc. From unglazed mouth edge of most green-glazed porcelain and bluish white porcelain, that is, unglazed neck, it can be seen that they are made by upside down firing. In addition, mouth edges of some implements are smooth, there is no glaze in one cycle inside them, there is exposed body at bottom foot, some are connected with sagger, and they are produced by upright heaping firing.

Yangwuling kiln mainly fire celadon, bluish white porcelain. The glaze is glazed evenly and smoothly, the glazing color is blue, the glazing quality is glossy, just like jadeware; from firmness and compaction rate of porcelain, the kiln temperature is about $1300{ }^{\circ} \mathrm{C}$. A small part of ceramics imitate $\mathrm{Ge}$ kiln glazed porcelain and adopt domestic cobalt pigment, the color is murky grey, with brown red stains. For example, green glaze lotus-petal design folded along the panel, green glaze is glazed inside and outside, jade-like stone thick and with glass texture, but the color is dark and gloomy, the glazing color is not even enough, and thickness is not uniform, there is exposed body, sand burning and flint red phenomena exist at unglazed inner bottom, it can be seen that reducing atmosphere is not enough in firing. 


\section{DECORATION PERFORMANCE AND CULTURAL MEANING}

Yiyang is located in Dongting Lake Plain, with long historical culture. The bred academy culture, poetic society culture, bamboo culture and Meishan culture nourishes a side soil and water and provides rich cultural literacy of Yangwuling kiln ceramics creation. Craftsmen of Yangwuling kiln ceramics reasonably and skillfully integrate local cultural elements into ware shape and ornamentation through extraction of local culture when they constantly pursue artistry and creation style. In specific decoration and cultural containing, poetic image and simple life portrayal can be seen; decoration techniques are rich and diversified; decoration methods include cutting, painting, blue-and-white and character decoration and so on. Decoration is not only based on traditional Chinese printing techniques and focuses on rhythm of reality and fantasy density and primary and secondary proportional relation, but also includes incisive and vivid expression for glazes, especially expression for implication of local culture is the only direct expression of one's own feelings; the writing is incisive and vivid, natural and bold; some ceramics combines craft and writing in accordance with characteristics of scenery so as to express the author's intricate thoughts as far as possible.

Yangwuling kiln ceramics are innovated by reference, for example, celadon mostly imitate Jingdezhen shadow celadon and Longquan celadon in decoration method, decorated with engraving, bamboo comb cutting, press back, hollow, plastics sticking and other process; Brown glaze stippling flower pattern in Yuan Dynasty follows and imitates decoration and embellishment characteristics of Changsha kiln, meanwhile it is blended into local culture and observes local humanity, landscape and historical tradition; for example, bamboo culture in Yiyang pursues elegance and carefree mood. Painting of blue and white porcelain reflects that Yiyang people watch bamboo, listen to bamboo and recite bamboo and express elegant cultural spirit pursuit of refined scholars. For another example, for blue and white porcelain of Yangwuling kiln, the color is simple and elegant, ornamentation takes enjoyable scenery, flowers and birds and plum blossoms, orchid, bamboo and chrysanthemu m as themes, the writing is free, with open-minded and romantic feeling of Hunan culture; there is no lack of mathe matical pursuit of Meishan culture in the expression contents. In addition, leaves of grass, flower patters, happiness and prosperity, auspicious words are involved extensively, which fully reflects combination and popularity of folk culture and poetic society culture.

Art themes of Yangwuling kiln ceramics are extensive, for example, flowers and birds, poems and calligraphy and so on are involved, which appropriately intersperses and enriches art language. The decoration is simple and crude, seemingly random hasty production does not lose mature image expression, integrated with seal cutting, calligraphy, poems, painting and other arts. The color-glazed porcelain is vigorous and steady, the painting technique is adept, writing of blue and white porcelain is merry and lively and the form is concise, which requires the creator to possess skilled techniques and superb skill to plan a structure. For example,
Qing Kang xi blue-and-white Pattern of tank "Fig. 2", the flowers expression and writing is frank and natural, even some casual, scattered in the air or water and forms an unique childish taste. With straight port, sloping shoulder, abdomen in, matched with arch dome, peach handle, folded rim mouth, the modeling is vigorous and mellow and full; followers are painted in the cover and abdomen and blue and white color is deep.

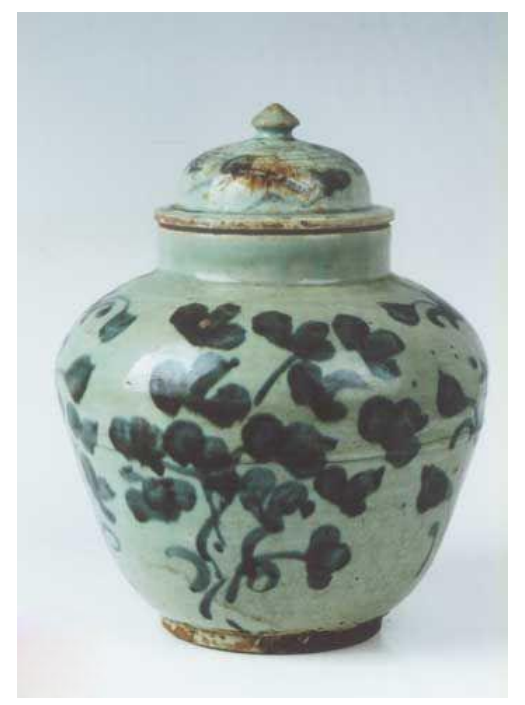

Fig. 2. Qing Kangxi blue-and-whitePattern of tank

Yangwuling kiln ceramics painted decoration does not only include flowers and patterns, but also has verses and articles reflecting local culture, folk custom and history, for examp le, "people send gifts to each other in four seasons and eight solar terms", which reflects folk custom characteristics of generous gifts and valuing feelings in local place where courtesy demands reciprocity as well as social at mosphere of treating others with earnestness and harmoniousness and friendliness. As another example, "this ceramic can contain flowers, many girls love him, they are seventeen or eighteen; you can take the fruit if you like", which reflects dense secular fun and romance.

\section{CONCLUSION}

Yangwuling kiln ceramics possess unique artistic charm. Although they are mainly used as practical tools and production defect exists in modeling and decoration, just due to hasty modeling and decoration showing specific style and features, plus confluence and fusion of northern and southern ceramics style, Yangwuling kiln ceramics both have ruggedness of northern ceramics and elegance of southern ceramics. Expression of local cultural and fusion of relevant art allows Yangwuling kiln ceramics to show their abundance and uniqueness. In a word, artistry of Yangwuling kiln ceramics is closely linked with local culture and environment, with certain historical value and cultural value. By virtue of its scale once, Yangwuling kiln is not inferior to Liling kiln and Tongguan kilin. Its downfall is roughly caused by impact of chinaware of the same kind and defect of local china clay. Nowadays, Yangwuling kiln has become an important part of Yiyang his torical culture. 


\section{REFERENCES}

[1] Pan Maohui. An analysis on the Yangwuling Cultural Site [J]. Jianghan Archaeology: 2012, 12

[2] Zhang Ning, Zhao Guanglin. A Brief Discussion on Jingdezhen Royal Kiln Blue and White Porcelain[J]. Jingdezhen Ceramic: 1993(Z1) : 49-51

[3] He Yuxiang. Yangwuling Ancient Kiln Site: Endless History and Culture [J]. China Culture Daily: 2015, 05

[4] Cao Jin, Zhao Yan, Liu Jinwei, et al. Research on Rise and Fall of Hunan Two Large Famous Kilns in Tang Dynasty [J]. Agricultural Archaeology: 1995(02) : 175-177

[5] Liu Wenbin. Aesthetic Expression of Painting Ceramic Decorations [J]. Chinese Ceramics: 2012, 48(05): 80-81

[6] Zhang Jingyao. Technology and Cultural Studies of Liling Soil Porcelain of Civilian Kilns [C].Hunan: Hunan Normal University, 2011. 22-37. 